\title{
Implementation of a Learning Assessment: Case Study of Applied Statistics Course in Industrial Engineering
}

\section{Dr. Behin Elahi, Purdue University, Fort Wayne}

Dr. Behin Elahi is an Assistant Professor, Ph.D. in Industrial Engineering, Purdue University at Fort Wayne . Previously, she was fixed-term instructor at Michigan State University (East Lansing, MI) teaching courses such a manufacturing plan and control, supply chain modeling and management. She got her Ph.D. in Industrial Engineering from the University of Toledo (Toledo, OH) in 2016. She has also a Master degree in industrial Engineering and was a consultant/ project manager of the Business Waste Reduction Assistance Program (BWRAP), a partnership between EPA, University of Toledo and Lucas County in Ohio from 2012-2016. She is a professional and an active member of the Society of Women Engineers, Society of Manufacturing Engineers, and Institute of Industrial and System Engineering. 


\title{
Implementation of a Learning Assessment: Case study of Applied Statistics Course in Industrial Engineering
}

\begin{abstract}
Assessment of student learning is an indispensable factor in determining whether students meet the desired standards of course content. This research focuses on researching the comparison of ABET learning outcomes in a lecture-based classroom course, which applies a traditional textbook, versus a mix of lecture-based and problem-based classroom course, which uses a textbook with more applicable case studies for the applied statistics course in Industrial engineering. The required data is gathered by faculty based on applied assessment tools such as project presentation and report, individual assignments, group assignments, in-class activities, and exams. This study was conducted across four semesters for the same course. The key findings from the study demonstrate that the integration of the applied case studies with a mix of lecture-based and problem-based teaching techniques improved the students' learning outcomes.
\end{abstract}

Keywords: Learning Assessment, Applied Statistics, ABET outcomes, Industrial Engineering

\section{Introduction}

It is broadly recognized that the applied statistics course is one of the most important quantitative subjects in the industrial engineering curriculum (Brown and Kass, 2009). Over the last decade, there has been raising attention given to the teaching and learning aspects of statistics course (Garfield and Ben-Zvi, 2008; Dinov and Christu, 2009; Bilgin, 2011; Harpe et al., 2012; Judi and Sahari, 2013; GAISE Report, 2016)

One of the essential components in the learning and teaching environment is an effective assessment that can promote learning as well as measure or certify outcomes (Garfield and Franklin, 2011; Clements and Cord 2013, Crisp et al. 2016). Assessment can also direct the approach students take to their learning (what, when, and how much they study), and can influence what they learn. Assessment in higher education plays a vital role, both in immediate and longterm learning (Crisp et al. 2016). Mentkowski et al. (2016) presented a comprehensive framework for an effective assessment and clarified elements of performance assessment such as determining clear learning outcomes and criteria for integrating subjects and abilities over time, designing learning objective by faculty, and providing accurate, diagnostic, and prescriptive feedback on performance.

While statistics education and specifically applied statistic course in industrial engineering has turned into a research area of increasing interest (Tishkovskaya and Lancaster, 2012; Patil et al. 2015) implementing effective assessments and achieving an appropriate balance between theory 
and application is a challenging task. In this research, by defining appropriate assessment tools such as applied research projects, group/ individual assignments, class activities, etc., two learning assessments by students and faculty are conducted. The results are analyzed to verify the effectiveness of applied assessment tools.

\section{Research Methodology}

In this research, the course of Applied Statistics for Industrial Engineering (IET 20500 undergraduate level, 3 credit course) was assessed at Purdue University-Fort Wayne.

This study was conducted across four semesters (each semester had 16 weeks) for the same course: in the Fall of 2013 and Fall 2014 for a lecture-based classroom course that faculty applied a traditional textbook, for 58 students and in the Fall of 2015 and Fall of 2016 for a mix of lecturebased and problem-based classroom course that faculty used a textbook with more applicable case studies for 54 students.

The ABET outcomes are considered in this research (see Table 1). Table 2 provides the criteria, learning outcomes, and assessment tools based on which students have been assessed.

Table 1. Definition of Applied ABET criteria for applied statistics course

\begin{tabular}{|c|c|}
\hline Criterion & Definition \\
\hline $\mathrm{a}_{1}$ & $\begin{array}{l}\text { An ability to select and apply the knowledge, techniques, skills, and modern tools of } \\
\text { industrial engineering. }\end{array}$ \\
\hline $\mathrm{b}$ & $\begin{array}{l}\text { An ability to select and apply a knowledge of mathematics, science, engineering, and } \\
\text { technology to problems that require the application of principles and applied procedures } \\
\text { or methodologies. }\end{array}$ \\
\hline $\mathrm{c}$ & $\begin{array}{l}\text { An ability to conduct standard tests and measurements; to conduct, analyze, and interpret } \\
\text { experiments, and to apply experimental results to improve processes. }\end{array}$ \\
\hline $\mathrm{d}$ & $\begin{array}{l}\text { An ability to apply creativity in the design of systems, components or processes } \\
\text { appropriate to the program objectives. }\end{array}$ \\
\hline $\mathrm{e}$ & An ability to function effectively as a member or leader on a technical team. \\
\hline f & An ability to identify, analyze, and solve technology problems. \\
\hline $\mathrm{g}_{1}$ & An ability to communicate effectively through writing. \\
\hline $\mathrm{g}_{2}$ & An ability to communicate effectively through oral presentation. \\
\hline $\mathrm{g}_{3}$ & An ability to communicate effectively through graphical communication. \\
\hline $\mathrm{k}_{2}$ & Commitment to timeliness. \\
\hline
\end{tabular}


Table 2. The course assessment criteria

\begin{tabular}{llll}
\hline Topics & Assessment Method & $\begin{array}{c}\text { General Education } \\
\text { Criteria }\end{array}$ & ABET C \\
\hline $\begin{array}{l}\text { Learn about categorical and ordinal data and } \\
\text { several ways for displaying such data and } \\
\begin{array}{l}\text { associated results of analysis in a meaningful } \\
\text { manner (L1) }\end{array}\end{array}$ & $\begin{array}{l}\text { Group assignment 1: } \\
\text { Questions 1,3 }\end{array}$ & $3.1-3.8$ & $\mathrm{a}_{1}, \mathrm{~g}_{3}$ \\
\hline
\end{tabular}

Learn about quantitative data and several ways for displaying such data and associated results of analysis in a meaningful manner (L2)
Group assignment 1:

Question 4, Midterm

Exam: Questions 4,11 multiple choice section, Question 10 Math section
$3.1-3.8$
$\mathrm{a}_{1}, \mathrm{~g}_{3}$

Group assignment 1:

Questions 2,3,5; HW05

Learn about measures of central tendency and dispersion (i.e. median, mean, sample mean, sample median, variance, standard deviation, quartiles, trimmed mean) (L3)

choice section, all questions; Midterm

Exam: Questions

$1,2,3,5,12$ multiple

$3.1-3.8$

$a_{1}, b, f$

Question 1,2,7, 11

Math section

Hw02 all questions,

Group assignment 2 all

questions, Midterm

formal probability rules, conditional probability, independent events, dependent events, multiplication rules for independent events (L4)

Exam: Questions

$3.1-3.8$

$a_{1}, b, f$

6,7,9,10 multiple choice section, Question 4

Math section

Learn about counting sample points: permutation and combination (L5)

HW01 all questions

$3.1-3.8$

$a_{1}, f$

Learning about total probability and Bayes'

Rule (L6)

HW03 all questions

$3.1-3.8$

$\mathrm{a}_{1}, \mathrm{f}$

Learn about random variable and probability models: Binomial Distribution, Poisson Distribution, and Exponential Distribution, being able to apply the related tables for finding Binomial and Poisson probabilities (L7)

Learn about Normal Distribution and Standard Normal Distribution, its application, being able to apply the related tables for finding normal probabilities (L8)
Final Exam: Questions

8-9; HW04, Midterm

Exam Question 8

multiple choice section,

$3.1-3.8$

$\mathrm{a}_{1}, \mathrm{f}$

Question 3,5,6,8,9

Math section
Final Exam: Questions

1-6; Group Assignment

3 all questions
$3.1-3.8$
$a_{1}, f, g_{3}$ 
Learn about Regression Model and analysis: (be able to find Sample correlation coefficient for a data set and the parameters of Estimated Regression Model) (L9)
Final Exam: Question 7; Group assignment 5 all questions
$3.1-3.8 \quad a_{1}, b, f$

Learn about Testing Hypotheses:

understanding $\mathrm{H} 0$ and $\mathrm{H} 1$ concept, (Being able to use Minitab software for checking normality test on data, hypothesis testing, when the ANOVA test is required.) (L 10)

Final Exam: Question3; Group assignment 6 all questions
$3.1-3.8$
$\mathrm{b}, \mathrm{c}, \mathrm{f}$

Be able to work effectively in a group project, selected a well-defined problem, use proper knowledge and skills, apply creativity and accuracy, write a clear, concise, and wellorganized report with professional language and style, free of typographical errors, and
Group Project Report
$3.5,3.7,3.8$
$\mathrm{d}, \mathrm{e}, \mathrm{g}_{1}, \mathrm{k}_{2}$ appropriate technical literature (references, etc.) (L11)

Be able to apply the lessons, learned, present the findings of the group project in an oral presentation and well-prepared audiovisuals (with introduction, body, and conclusion), respond to audience questions effectively, dress appropriately, communicate clearly,

Group Project presentation
$3.5,3.7,3.8$

$\mathrm{d}, \mathrm{e}, \mathrm{g}_{2}, \mathrm{k}_{2}$ have committed to timeliness, commitment to quality work. (L12)

Various applied research projects were defined for this course and students worked on them as a team and at the end of the semester they presented their work.

\section{Example of Students' research projects:}

- Research on "Case study: A statistical quality control project"

- Solving the bearing failure problem for a global market leader in electromagnetic clutch and brake technologies for demanding applications worldwide, located in Columbia City, IN"

- Research on "Apple Vs Google Stocks: A statistical analysis”

- Research on "Case studies: Lean Manufacturing"

- Finding a solution for a better control of storage and purchasing of dies for company in supplying magnet wire for manufacturers and located in Fort Wayne, IN.

- Doing a research project on identifying the cause of declined produced parts per labor hour for the assembly line of a vehicle group of a company located in Auburn, IN.

- Research on "Data analysis and Prediction of Tornado in State of Oklahoma, using Poisson Distribution"

- Research on "Customer data analysis and retention for a web-based Company" 
Based on the students' performance in class activities, individual/ group assignments, research project and written report, and exams, faculty conducted a course learning assessment.

To evaluate the students' learning outcomes before and after changing the text book and teaching technique, the Kolmogorov-Smirnov normality test and paired-t test (as sample size is less than 100) were applied. The null hypothesis (Ho) states that there was no difference between the results of two different teaching approaches. The alternate hypothesis (H1) states that there was a significance difference between the two different teaching approaches.

\section{Result and discussion}

In this section, the result of the course learning assessments for the two different applied teaching techniques by faculty are presented. Then, the gathered data is tested for Normality check using Kolmogorov-Smirnov normality test. Then, the paired-t test is applied. These tests are conducted in MINITAB 17 software.

Table 3 displays the result of the assessment by faculty based on individual assignment, group assignments, exams, project presentation, and the written report when two different teaching techniques including a) a mix of lecture-based and problem-based classroom course that faculty used a textbook with more applicable case studies (Fall 2015 and Fall 2016); b) a lecture-based classroom course that faculty applied a traditional textbook (Fall 2013 and Fall 2014) are applied. After collecting the results, as mentioned earlier, Kolmogorov-Smirnov normality test is applied to evaluate whether the difference of such a paired data set has normal distribution or not. Figure 1 shows the result of this section. Here, the null hypothesis (data has a normal distribution) is accepted. Thus, we can apply paired-t test to compare the applied two teaching techniques. This result is displayed in Table 4.

As the $P$-value (0.000) is lower than $\alpha(0.05)$, then the null hypothesis is rejected in this research. A comparison of a lecture-based classroom course that faculty applied a traditional textbook (Fall 2013 and Fall 2014) versus a mix of lecture-based and problem-based classroom course that faculty used a textbook with more applicable case studies (Fall 2015 and Fall 2016) indicated statistically significant improvements in student's learning outcomes at the $95 \%$ confidence level. 
Table 3. The results of the course learning assessment by faculty (Average out of 4)

\begin{tabular}{lcc}
\hline Learning Objectives & Teaching technique a & Teaching technique b \\
\hline L1 & 3.97 & 3.62 \\
\hline L2 & 3.22 & 3.12 \\
\hline L3 & 3.14 & 3.00 \\
\hline L4 & 3.00 & 2.99 \\
\hline L5 & 3.40 & 2.98 \\
\hline L6 & 3.31 & 3.16 \\
\hline L7 & 3.23 & 2.99 \\
\hline L8 & 3.73 & 3.30 \\
\hline L9 & 3.76 & 3.40 \\
\hline L10 & 3.22 & 3.21 \\
\hline L11 & 3.42 & 3.20 \\
\hline L12 & 3.34 & 3.15 \\
\hline
\end{tabular}

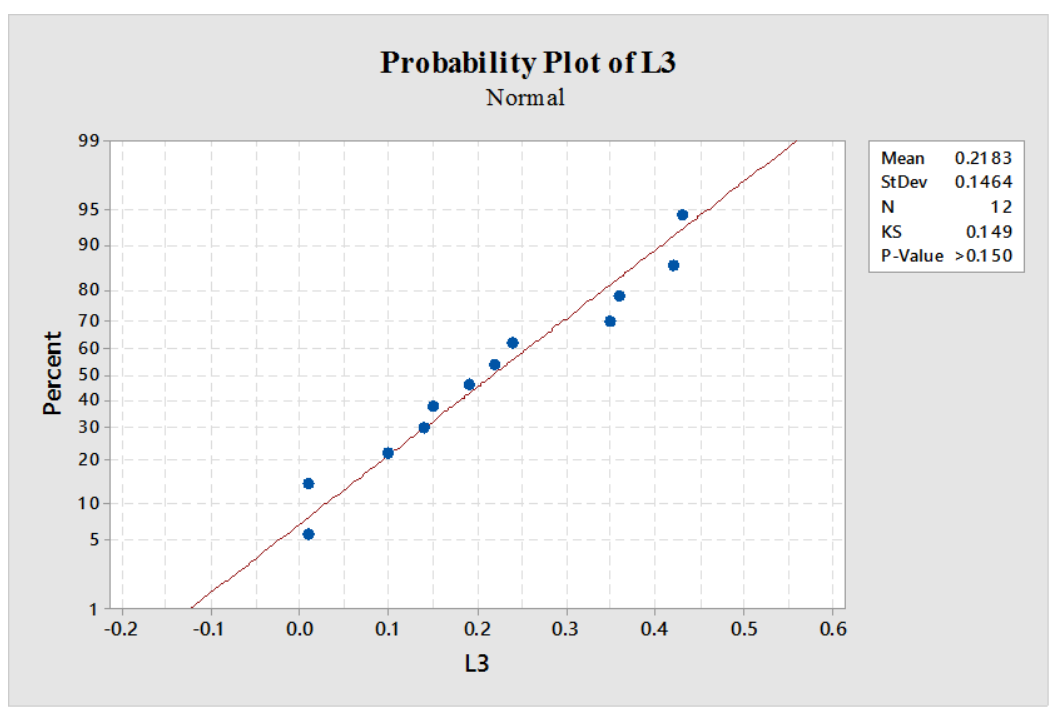

Figure 1. The results of Kolmogorov-Smirnov Normality test 
Table 4. The result of Paired T-Test

\begin{tabular}{llllll}
\hline Teaching Technique & Mean & Standard Deviation & Standard Error of Mean & T-Value & P-Value \\
\hline A & 3.3950 & 0.2855 & 0.0824 & 5.17 & 0.000 \\
B & 3.1767 & 0.1924 & 0.0555 & & \\
Difference & 0.2183 & 0.1464 & 0.0423 & & \\
95\% CI for mean difference: $(0.1253,0.3114)$ & & & \\
\multicolumn{2}{l}{ T-Test of mean difference $=0(\mathrm{vs} \neq 0)$} & & & \\
\hline
\end{tabular}

\section{Conclusion}

In this study, course learning assessments by faculty were examined for applied statistics course. The results validated that using an integrated teaching technique which focuses on applicable case studies, and a combination of lecture-based and problem-based methods versus traditional lecturebased classroom course enhances the student learning outcomes significantly. Some limitations of the study include the location and sample size in Fort Wayne, Indiana. A larger, more diverse sample would provide broader results. Further research would provide deeper insights into this area.

\section{Reference}

Brown, E., Kass, R., 2009. What Is Statistics? The American Statistician. 63(2), 105-110.

Bilgin, A.A.B., 2011. Does learning in statistics get deeper or shallower? Intl Jnl of Educational Mgt 25, 378-389. doi:10.1108/09513541111136658.

Clements, M. D., Cord, B. A., 2013. Assessment guiding learning: developing graduate qualities in an experiential learning program. Assessment and Evaluation in Higher Education, 38(1), 114-124.

Crisp, G., Guàrdia, L., Hillier, M., 2016. Using e-Assessment to enhance student learning and evidence learning outcomes. International Journal of Educational Technology in Higher Education,13-18. doi:10.1186/s41239-016-0020-3.

Dinov, I., Christou, N., 2009. Statistics Online Computational Resource for Education, Teaching Statistics, 31(2), 49-51.

Garfield, J., Ben-Zvi, D., 2008. Developing Students' Statistical Reasoning: Connecting Research and Teaching Practice. Springer Science \& Business Media, 21-43.

Garfield, J., Franklin, C., 2011. Assessment of Learning, for Learning, and as Learning in Statistics Education, in: Batanero, C., Burrill, G., Reading, C. (Eds.), Teaching Statistics in School Mathematics-Challenges for Teaching and Teacher Education, New ICMI Study Series. Springer Netherlands, pp. 133-145. doi:10.1007/978-94-007-1131-0_16.

GAISE Report, 2016. Guidelines for Assessment and Instruction in Statistics Education (GAISE) Report. The American Statistical Association. 
http://www.amstat.org/asa/files/pdfs/GAISE/GaiseCollege_Full.pdf (Accessed 2.10.2017.)

Harpe, S.E., Phipps, L.B., Alowayesh, M.S., 2012. Effects of a learning-centered approach to assessment on students' attitudes towards and knowledge of statistics. Currents in Pharmacy Teaching and Learning 4, 247-255. doi: 10.1016/j.cptl.2012.05.002.

Judi, H.M., Sahari, N., 2013. Student Centered Learning in Statistics: Analysis of Systematic Review. Procedia - Social and Behavioral Sciences, 13th International Educational Technology Conference 103, 844-851. doi: 10.1016/j.sbspro.2013.10.406.

Mentkowski, M., Diez, M.D., Lieberman, D., Mace, D.P., Rauschenberger, M., Abromeit, J., 2016. Conceptual Elements for Performance Assessment for Faculty and Student Learning. In Assessing Competence in Professional Performance across Disciplines and Professions, edited by Wimmers, P.F., and Mentkowski, M., 11-38. Innovation and Change in Professional Education 13. Springer International Publishing. doi:10.1007/978-3-319-30064$1 \_2$.

Patil, P., Mulimani, D., Desai, B.L., 2015. Prominent Assessment of Students Learning and Statistical Analysis of Quizzes, in: Natarajan, R. (Ed.), Proceedings of the International Conference on Transformations in Engineering Education. Springer India, 567-568. doi:10.1007/978-81-322-1931-6_69.

Tishkovskaya, S., Lancaster, G., 2012. Statistical education in the 21st century: a review of challenges, teaching innovations and strategies for reform. Journal of Statistics Education 20, $1-56$. 